\title{
Embodying Cyberspace: Making the Personal Political in Digital Places
}

Wendy Harcourt and Ximena Argüello Calle

\section{INTRODUCTION}

Our chapter builds on an intergenerational transnational exchange about how feminists can create safe places of engagement via the internet as part of embodied active research processes. The focus of the chapter is two stories separated by over two decades that illustrate how safe feminist and queer places are co-created and embodied as vital for connections and communication in cyberspace. Inspired by feminist geographies, we employ the term "place" as a term to explain a virtual sense of belonging where people could explore possibilities of embodied politics within cyberspace. We follow Doreen Massey in differentiating space as the "simultaneous coexistence of social interrelations", from place as the

W. Harcourt · X. Argüello Calle $(\bowtie)$

International Institute of Social Studies, Erasmus University Rotterdam, The Hague, The Netherlands

e-mail: arguellocalle@iss.nl

W. Harcourt

e-mail: harcourt@iss.nl

W. Harcourt et al. (eds.), Feminist Methodologies, Gender, Development and Social Change, https://doi.org/10.1007/978-3-030-82654-3_5 
hosting of social interactions that are unique and particular that "will in turn produce new social effects" (Massey, 1994: 168). Our two stories illustrate how embodied sexuality and gender power relations are shaped in the digital world. It explores the potential for feminists in online worlds to create places where individual and collective transformative processes are possible.

The chapter brings into conversation what is similar, as well as what is particular and unique to each of our stories. Women on the Net (WoN), the first story, comes from the very early days of the internet in the late 1990s when feminists began to see the internet as a possibility for transnational organizing. At that moment transnational feminism was beginning to explore how to connect in the digital world, and where internet (basically just email) was (tentatively) being seen as a potentially accessible and safe place in cyberspace where feminist dialogues on intimate and political levels could engage.

Cuir Copensantes (CC), the second story, explores the process of organizing feminist and cuir/queer ${ }^{1}$ research digitally in 2020 during Covid19. In this historical moment, cyberspace becomes the only completely safe space for social interaction (no risks of infection). Online platforms (particularly video call platforms) offer the possibility to create connection and be "close" among physically "distanced" people during chaotic times. The term "physically distanced" speaks both to Covid-19 measures and also for cuir (queer) people to the idea of distance as safe and where conversations about intimate emotional lives can be expressed safely.

The chapter reflects on how feminist methodologies enabled us to participate in unorthodox research processes that crossed different borders of time, space, knowledge and embodiments as we created feminist digital places that unpacked meanings of technology, gender and

${ }^{1}$ Following Sandra Harding's work (1992) on situating knowledge, the project paid particular attention to the situated context and embodiments of the participants. For this reason, the word "cuir" was employed as a feminist (and cuir/queer) act. While "queer" no longer carries a negative connotation in the Spanish-speaking world and thus, its appropriation does not represent a political act, the term "cuir" is an "epistemological point of departure, while also acknowledging its insufficiency to speak from the global South" (Chernysheva et al. as cited in Trujillo, 2016: 5). "Cuir" speaks to the necessity to situate struggles and decolonize the concept of "queer", all without disregarding the transformative potential and the political history of the term queer. Employing "cuir" was a decision informed by a feminist (and cuir) embodiment that has developed in me (Ximena), a strong desire to stay loyal to situatedness of knowledge while still seeking inspiration from others' resistances. 
sexuality. As we tell the stories of how these digital places were created, we explore the possibilities as well as the troubling tensions in digital communications. We ask: what does digital embodiment mean? How is care constructed and experienced online? What does it mean to build trust digitally? How safe is safe as we communicate through technologies and machines? How do feminist ideas travel over time as well as between physical places and cyberspace? How do these spaces become border-crossing places?

Our methodological approach reflects our strong feminist ethics which we believe are required to build places of trust and care. Such an ethical approach enabled us to create and embody digital safe places. It is impossible to disentangle the feminist and the queer/cuir approaches that informed this safe place that provoked and intrigued us throughout the process. Our experiences, ways of seeing and interacting informed a particular form of understanding. In writing together, we intentionally aimed to live our feminist values of empathy and care that were the base of our ethical exchanges. We simultaneously celebrated our struggles and wounds by respecting our diversity. Our shared feminist ethics also helped us to breakdown hierarchies of age and academic positioning in our coproduction of the chapter. We believe in the importance of raising our voices as feminists and also to embody the transformative potential of doing/researching/living otherwise. ${ }^{2}$ In this sense, the chapter has the ambitious intention of bringing our diverse yet collective digital subjectivities to a discussion on feminist methodology through stories across time and place.

In this chapter, we decided to use art with a feminist and queer/cuir political intention of not only dismantling the traditional forms of knowledge production, but also questioning (and queering/cuiring) the concepts of talent and expertise. We propose that art should be seen not as a professional construct that requires talent and artistic learning, but instead can be embraced as self-expression that can be freely explored, in ways that disrupt academic boundaries and cross borders of what is acceptable knowledge. We see art as a powerful tool for making visible

\footnotetext{
${ }^{2}$ We use the evocative term "otherwise" inspired by post-development scholars, such as Arturo Escobar (2007) and decolonial feminists such as Catherine Walsh (2016). Here it refers to alternative ways of doing research that are not ruled by methods that rely on empirical observation that is considered objective, or relate to some universal idea of knowledge set by the Western academy.
} 
what is disregarded or labelled as "invalid" or "negligible". Through our drawings we present art as a fluid, diverse and malleable tool with political intent. We use our drawings exploring the transformative potential of art as "contagious" in its ability to carry political meaning. Far from remaining innocent or actionless, the transformative desire embedded in art can mobilize embodied intentions and emotions and generate empathy in different ways than descriptive text.

\section{BACKground TO WOMEN ON THE NeT (WoN): A Feminist Research Project FUNDED BY UNESCO I997-I999 (WENDY)}

Women on the Net (WoN) was set up by UNESCO in the late 1990s in order to understand the feminist approach to the new information and communication technologies (ICTs). WoN was a meshwork of connections with 20 women and men contributing to the (English) language listserv (an electronic mailing list which allows a sender to send one email to the whole list), connected from the Pacific, Asia, Africa, Latin America, Europe and the USA through the auspices of UNESCO. I (Wendy) was the coordinator of the project which was shaped through conversations with Lourdes Arizpe, the deputy Director General of UNESCO. Arizpe saw WoN as part of a new "Gaia of cultures" made possible through this new world of ICTs (Harcourt, 1999: 22).

The WoN research was undertaken at a particular moment at the end of the twentieth century. The period was imbued with the rhetoric about the new millennium with the internet as a shiny new global technology that was opening up the freedom to create and build new civic places in cyberspace. As a UN funded project, the scope was unapologetically large. The remit was to create a cyber culture which could foster and create caring relationships between genders, generations and communities. The project presented the internet as a political tool that would "empower" women from the Global South and marginal communities in the Global North. The WoN research was undertaken on a listserv that shared ideas on how to advance a gendered local and global perspective to cultural and policy debates on the internet. It was intended to illustrate how feminists could navigate the internet in a period where feminists were deeply suspicious of capitalist, patriarchal and military roots of the technology. WoN embraced a science and technology feminist perspective. Donna 
Haraway's concept of the cyborg (1985/1991) (see below) was adopted in order to analyse the different researchers' personal and intimate histories and experiences to counter the refusal of radical (eco)feminists who were advocating a return to nature.

The research project led to nearly 3000 email exchanges that crossed personal, spatial, political and professional boundaries. We debated who would be enabled to speak? Who would remain silent? How could we use feminist theory to strategize? How did the circuits of meaning we were creating defy academic boundaries? We tried to bring together the technical, the theoretical and the practical in our two years of discussions.

Who joined the project was somewhat haphazard. Mostly they were women (two men) in their 20 s to 40 s, the majority from the Global South, from different race, class and professional backgrounds-technicians, engineers, activists and academics. I (Wendy) sent out a general invitation to different feminist networks asking who saw the new ICT as a potential political tool for feminists. What kept us together over the two years was our curiosity and hope that ICTs could support transnational ways of communicating among feminists, from wherever we were based-as long as there was the infrastructure. Three of the group were engineers who were providing the infrastructure. The debate began on technical and political grounds, but as we shared stories, we started to build trust and to share information about our more intimate lives.

It felt exciting (and new in the 1990s) to create a place-based global community that was intentionally exploring how to link the different places where the participants were physically based in a place of global political possibility in cyberspace. The community looked at how women could understand themselves as active agents harnessing this new technology. Many questions that seemed so challenging and important then appear now as somewhat extraneous: Can values of care and love be filtered through metal machines and optics fibres? How can women softwear the new technologies? Can we get the right mix of imagination and technology? How will the internet allow cultures to be carried across countries and continents? Can feminism create a global world of one's own?

What is important to emphasize over twenty years later was that it was a new process to be able to use computers to write emails that encompassed personal as well as professional concerns. It also felt excitingly strange to be able to connect so rapidly without using the expensive telephone or having to meet physically. 
As WoN evolved through our messaging on the listserv we decided not only to write the required report for UNESCO but also to publish a book-Women on The Net: Creating Culture in Cyberspace with Zed Books-a London based radical development publishing house. As we created a place to explore these ideas, we felt we were learning as we were creating, thinking as we were running, embracing an emerging sense of being part of the global not yet fully understood. The report and the book reflect this excitement and engagement. We proclaimed at the end: "the Internet has become an increasingly accessible learning space, a place to network, and to gain power and strength ... to create a new politics emanating from place" (Harcourt, 1999: 223-225).

\section{Background to Cuir Copensantes (CC): Recalling [RECORDANDO], SENSING [SINTIENDO] AND HEALING [SANANDO] TOGETHER [JUNTES] (XIMENA)}

Inspired by a previous experience of creating and participating in a queer safe place, ${ }^{3}$ I (Ximena) decided to employ it as a method of research and as a form of moving away from normative ways of knowledge production. Creating a safe place represented an opportunity to think about a research paper $(\mathrm{RP})^{4}$ differently. The attention was not centred on the production of a thesis to obtain a master's degree, but on co-creating a common place of sharing and healing where people feel comfortable and safe, and from where knowledge would be constructed collectively.

CC was designed, co-created and written in 2020, and thus, all its stages were shaped and informed by the global Covid-19 outbreak. We experienced and embodied the measures to reduce the risk of infection, the new strange and unknown "socionatures"-a term recognizes how the natural world, in this case the virus, shapes social relations-and the diverse emotions. When travelling to Ecuador, as originally envisaged, was not possible for me due to Covid-19, the digital space became our site of encounter. Six cuirs - five based in different cities of Ecuador and myself

\footnotetext{
${ }^{3}$ This safe place was organized by the 2019-2020 master students who were part of the Sexual Diversity Committee of the International Institute of Social Studies. The objective was to support each other during the academic journey, and to reclaim visibility and space. We shared stories, mostly related to sexuality and the challenges of our own experiences. It quickly became a network of connection and relief.

${ }^{4} \mathrm{~A}$ research paper or $\mathrm{RP}$ is the equivalent to a thesis for obtaining a master degree.
} 
in The Hague-engaged digitally in the construction of a safe place to share stories, feel accompanied and become Copensantes (co-thinkers). We chose the term Copensantes because it captures the collective decision to recall, reflect, feel, experiment and be rebellious together. Art, storytelling and art as storytelling were at the centre of the exchanges. The discussions were about the implications of the heteronormative understandings extracted from the nature/culture divide, that locate cuir bodies as "unnatural" and upon which violence and discrimination against these bodies rest. The narratives oscillated between the personal and the political, abstract theory and material experiences, crossing the borders of time and space between past emotions and experiences and Covid-19 times.

The project had four stages with approximately twenty online encounters held via Zoom, from July to November 2020. Some of the conversations had a group format and others were one-on-one discussions (all in Spanish). The entire process was informed by the ethics of care and concern (Sörensson \& Kalman, 2018) so that the Copensantes also engaged in the writing process, either by the online participation in the seminar where the progress of the RP was presented, or by WhatsApp, where reflections, discussions and comments travelled across space. A final Zoom encounter served to collectively review the draft that was translated from English to Spanish by one of the Copensantes to safeguard the confidentiality and the accuracy of our stories. After the formal project ended, ongoing conversations are leading to its possible continuation or its replication with queer/cuir local organizations in Ecuador.

\section{Feminist Genealogies}

While WoN and CC inhabited different eras and were formed through different technologies, the projects shared the goal of politicizing and embodying cyberspace through very different interactions and embodiments. In both projects we created a place of intimacy and connection in order to explore our embodied lives as expressed through digital communication. In these discursive explorations the importance of a safe place emerged, as part of feminist and queer resistance. This politics of place grounded and connected our feminist and queer/cuir lives, and our networked connections, where the body as place (in the flesh or digital) could be embraced as the first entry point to feminist and queer/cuir political change.

At the heart of both stories is the feminist adage that the personal is political as the participants used different digital formats to explore images 
and meanings that allowed an exploration of the embodied self, paying attention to emotions and intimate understandings of difference, seeing the digital world as an ecology, stretching the idea of bodies beyond the material.

The chapter is deeply shaped by our theoretical interest in how feminists create new forms of ethics in processes of knowledge production. Working across time, our two different narratives build on diverse situated, contextual and intersectional identities in the navigation of digital connections that are informed by our collective and individual feminist positionality. Both narratives are about building a safe feminist place in order to share personal and political concerns. The ethics of care and concern which underline the stories and the reasons for writing the chapter were shared so that the sense of safety and well-being of the participants (particularly for CC) was integral to the research.

We both experienced safe places as a possibility for border crossings during which the assumed boundaries between being a researcher and a participant began to blur, involving a complex process of self-reflexivity. At times writing as researchers, theorizing and analysing stories, but at other times speaking from our own experiences, our feminism and our queer/cuirness (see Fig. 5.1). And in writing this together we engaged in the messy process of being ourselves as writers who are sharing knowledge production from very different positionalities yet seek to produce something in common. In this we are never not ourselves, even given the many layers of identity that inform the way we navigate everyday encounters, including research, our relations to the other, and to the people in our stories. We acknowledge and embrace the impossibility of "detaching" from our subjective selves when producing knowledge.

Within these safe places, as well as while writing this chapter, we embrace a self that is "un-centered, un-certain, not entirely present, not fully representable: this is not a self that can be revealed by a process of self-reflection" (Rose, 1997: 314). Thus, our reflections are hesitant, at times contradictory but allow us to push forward in exploring what the digital space can offer to feminists. The writing of the chapter is part of the co-constructing identity in a relational process where positionality is a fluid process.

We could write together because of our formal connection with International Institute of Social Studies (ISS) and our shared interest in feminist and queer activism. But going deeper, we also came together because of our love of story writing and our desire to bring that love 


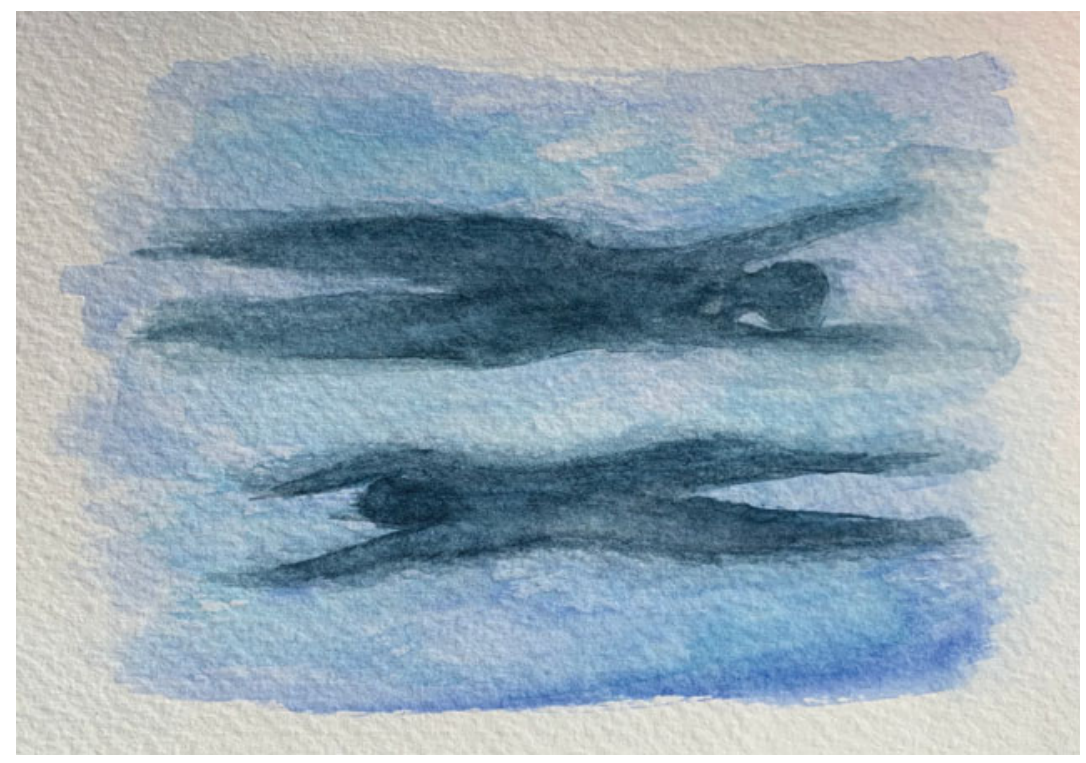

Fig. 5.1 Melting on water by Ximena

This is how I see our desire for fluidity. Disrupting fixities and embracing the way water teaches us to be, to melt. To feel ourselves unweighted and floating with no constraints, without binaries, without norms. That fluidity allows us to be one with our surroundings, to relate with the environment differently, letting it to be part of us and being part of it. To create deep connections that penetrate our souls, healing us and guiding our journeys of learning about the world

into feminist academic writing. Theorizing through stories helps to make knowledge more relatable and shows that theory is not an "abstract" thing "out there" but is present in our everyday lives.

What was key to our shared way of doing feminist research is using first person narrative and story writing. Sitting together in The Hague in Wendy's sitting room or meeting over Skype or zoom in digital places, we recognized the importance of pushing academic rules of what counts as knowledge and expression and the need to experiment beyond formalist writing. In these places, we oscillated between the personal and the political, and we went far beyond our initial professional relationship. The process of writing this chapter together as two feminists who believe in the potential of embodied action, was part of our resistance to the 
normative, open and curious to see what opportunities writing together about cyberspace could bring to our way of being.

Our drawings which accompany this chapter are also an attempt to probe beyond the academic text. We draw not as artists but as feminists who are trying to capture the sensing/feeling informing our subjectivities through these images. The drawings express our imaginings of the emotions and connections shaped by personal/political specific historical moments and our feminist theorizing.

We chose to use drawings in our text as it allowed us to slow down, reflecting further on what we are sensing and feeling as we gave ourselves time to recall when we wrote about our experiences then, linking the two historical dimensions. The drawings are relational across time connecting to our past and present selves and discovering those connections in art. Going beyond words allowed the unexpected to emerge and to find other ways to communicate as the drawings capture feelings words cannot. For us the drawings are experimental and have fluid meanings, they are what the reader wants to see in them. As feminists committed to doing research otherwise we gave ourselves permission to use art as part of our reflections and contributions to the book. It felt courageous to do so, as art is not what we would see as our "expertise". At the same time, we see the power of art. We were inspired by the illustrations in Rosa and Lillian's chapter (Chapter 11) and also by pedagogical approaches to knowledge production using art in the class room.

From these shared understandings, our writing and our projects have been inspired by specific feminist theory. WoN was directly inspired by Haraway's Cyborg Manifesto (1985/1991). The Manifesto invites feminists to look at how technology is infused with the political cultural and material embodied experience. The manifesto influenced a generation of feminists. Haraway uses performative and autobiographical language to describe the cyborg in materialist feminist terms that is deliberately ironic. She defines the cyborg as a "cybernetic organism"; a "hybrid of machine and organism", a "creature of lived social reality", and a "creature of fiction" (Haraway, 1991: 221).

The cyborg is both metaphor and real-life being and Haraway proposes that "cyborg imagery can suggest a way out of the maze of dualisms in which we have explained our bodies and our tools to ourselves ... It means both building and destroying machines, identities, categories, relationship, spaces, stories" (Haraway, 1991: 223).

Haraway's cyborg represents different forms of border crossings that change late twentieth/early twenty-first century feminist experience in 
important ways. Haraway proposes several "border crossings" (1991) which has continued to elaborate in her writing about companion species as well as cyborgs. She points to the blurring of divisions between humans and animals due to increasing human experimentation and exploitation of animal bodies for science and medicine, for example medical transplants that use baboon or pig organs. She also analyses how stealthily machines have become part and parcel of our lives and bodies, where the natural and artificial blend and "[o]ur machines are disturbingly lively, and we ourselves frighteningly inert" (Haraway, 1991: 228). Technology has become so much part of our lives that we do not notice it-so much so that we accept its encroachment as normal, such as the pervasive level of stress due to our reliance on consuming technology everyday through computers and social media. These technologies erode the distance between the physical and the non-physical. Haraway invites feminists to analyse this emerging technoculture which permeates our lives as feminists looking at both the negative dominations but also at the possibilities of progressive politics if we recognize "the machine is us, our processes, an aspect of our embodiment" (Haraway, 1991: 180).

Haraway appealed specifically to the Global South and women of colour as leading cyborgs in the new age of heavy technology. Such a direct appeal cut through the dominance of the colonial west was embraced by the WoN project. WoN challenged the assumption that the internet belonged only to the geeky "cowboys" of Silicon Valley and military technology. WoN resonated with Haraway's suggestion that the internet (ICTs) opened up possibilities for a collective imagination of feminists, particularly from the Global South, and enabled the participants to speak about the internet with its intimate and political dangers and possibilities. Inspired by the cyborg image, WoN debated the imaginative possibilities of the personal and political in a modern technoculture that could connect feminists in different parts of the world. WoN saw the digital world as allowing for greater feminist political engagement, expanding the idea of the material embodied self and of collective feminist communities. The idea of being both human and machine felt like science fiction had arrived in ways that enabled our different voices and experiences to challenge powerful white western male dominated spaces, changing what they looked and felt like (see Fig. 5.2).

Twenty years later, during Covid-19 and as part of a MA research project at ISS, a similarly audacious idea of finding possibilities to exist in 


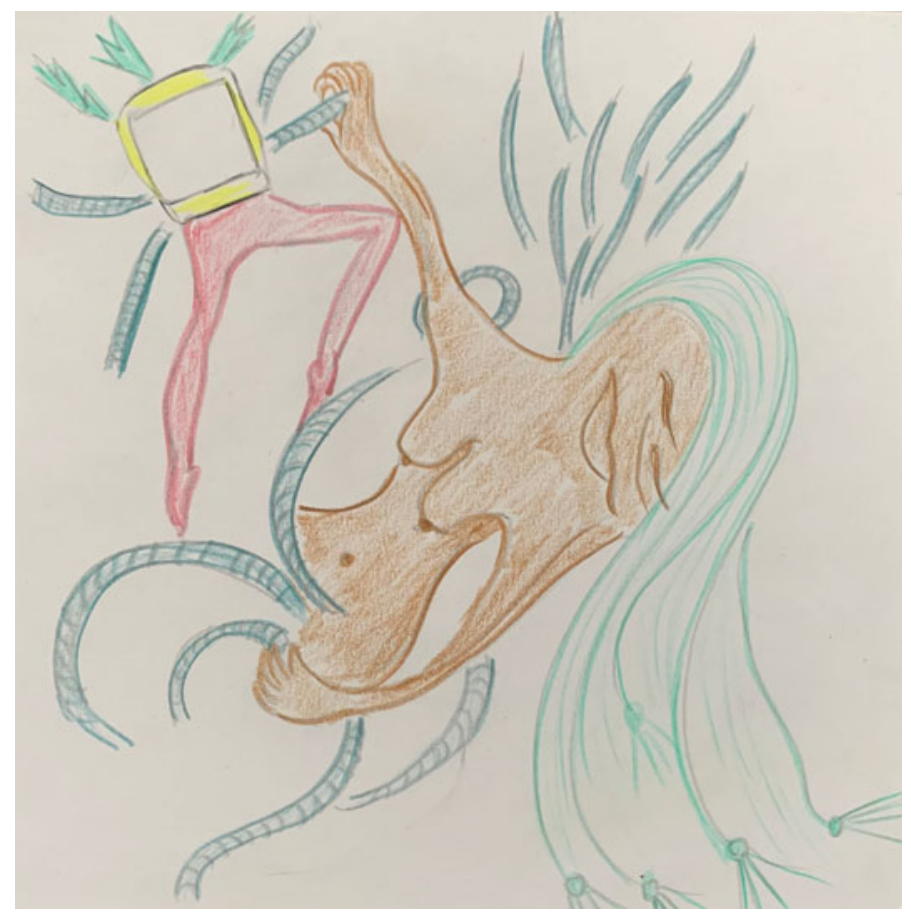

Fig. 5.2 Cyborg Melodies by Wendy

This picture recalls for me the feelings of wonderment at being connected to others while also being pregnant and being confined to bed, and then later as a mother breast feeding while still connecting to my network in the WoN project

the digital space, to connect, to be political was explored by six Ecuadorian cuirs in CC. Like with $\mathrm{WoN}$, in $\mathrm{CC}$ digital exchanges generated a place of border crossings: the geographical, the personal, the political, the conventional, the heteronormative, the natural, the artificial, to mention only some, and gave the opportunity to exert a political power through embodying the "machine" and crossing the borders, as Haraway (1991) invites.

The CC project was specifically influenced by feminist theorist Catriona Sandilands' questions about queer ecologies. By sharing stories and exposing wounds, CC problematized the culture/nature divide and the heteronormative understandings that are abstracted from it. As Sandilands (2005: 3) states, once the culture/nature binary is disrupted, the 
constructed meanings and conceptions that are ascribed to bodies can also be unpacked. With this, social inequalities and violence against queer/cuir bodies that rest upon the natural/unnatural distinction can be unveiled (Stein, 2010: 286) and resisted through employing Haraway's concept of natureculture ${ }^{5}$ (Haraway, 2003). In CC the role of art was essential, as it allowed the Copensantes to explain the forms in which "queernaturecultures" (Bell, 2010: 143), or rather cuirnaturecultures, informed injustices but also released the force to reclaim the body and its cuirness. The possibility of "masculinity" and "femininity" to coexist in flowers, the difficulty of explaining the role of bees and external agents in flowers' reproduction under heteronormative understandings, the freedom that emanates from a flying dandelion puff that disintegrates in the air, are some of the rebellious cuirnaturecultures that Copensantes depicted in artistic forms and that also inspired their desire for denouncing violence and resisting heteronormativity in CC and in their everyday lives.

CC employed art as a medium to explore wounds, memories and experiences (see Fig. 5.3). By crossing the border of the "conventional" methods of research, the digital exchanges acquired a different dimension and allowed the unspeakable not only to be said but to join a collective political intention. As a fluid, diverse and malleable tool, art allowed the Copensantes to feel unrestricted when sharing stories, therefore art contributed to CC's main aim: to resist constraints and limitations.

At the same time, by generating empathy and solidarity, art made CC an emancipatory environment. The power of art allowed the embodied emotions to travel and be embodied by those who witness it. According to Eisner (2008: 11) art can "generate a kind of empathy that makes action possible". In this sense, sharing stories through art and perceiving them through their situatedness allowed CC to produce "difference and equality, at the same time" (Lorenz, 2012: 17). For instance, CC hosted a dance performance where one of the Copensantes was able to express his embodied emotions resulting from the restrictions he experienced as cuir during Covid-19. The search for freedom, the despair, the pain, the courage he experienced were unavoidably embodied by its audience (the other Copensantes and the attendees to my RP seminar), and translated

\footnotetext{
${ }^{5}$ The concept of naturecultures as proposed by Donna Haraway contributes to disrupting the existing "binary opposition and hierarchy of nature and culture" (Harcourt \& Bauhardt, 2019: 9-10) and look instead at how these concepts are mutually informed and "co-producing each other" (ibid.).
} 


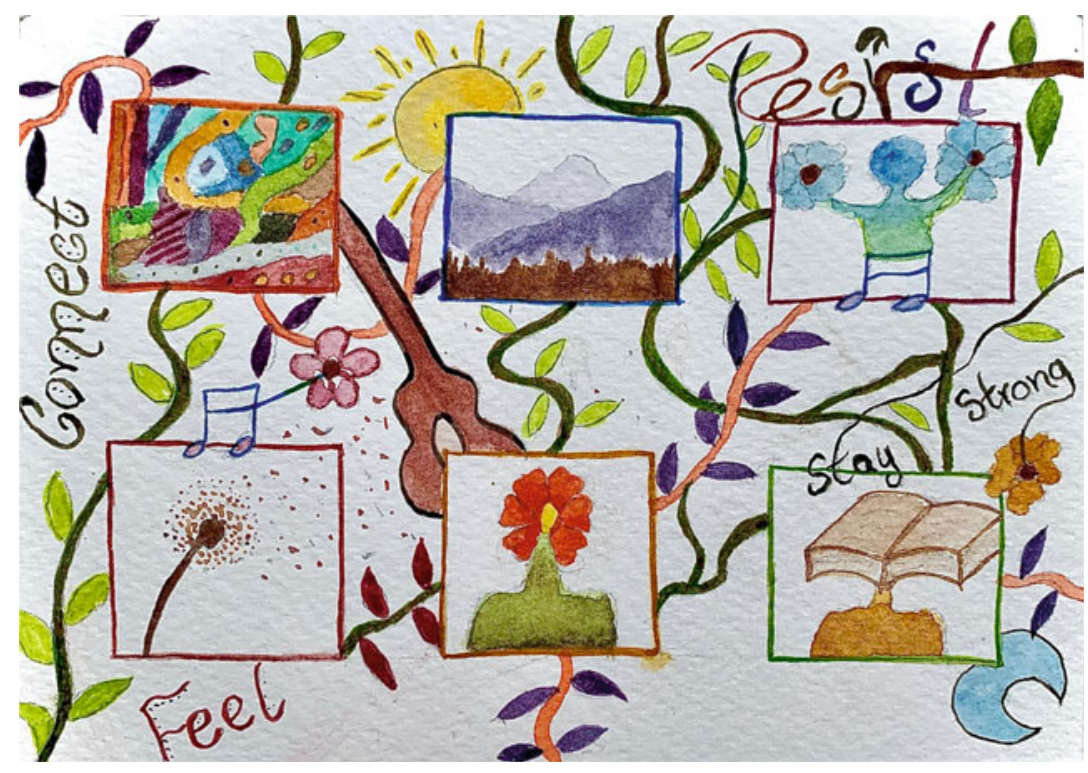

Fig. 5.3 Cuir, digital y floreciendo (Cuir, digital and flourishing) by Ximena This drawing reflects the isolation and confinement within Zoom squares. But it also depicts the disruptive potential of art as a medium to connect, resist and break boundaries in the cyberspace when also finding the beauty of our diverse histories, identities and subjectivities, together...

into tears and empathy behind a screen from where we observed, feeling profoundly moved.

\section{Feminist Entanglements-Across Time and Place}

In order to create a dialogue between our experiences we now share four moments which we see as pivotal to the two different projects. The first set of moments looks at the different embodiments and confinements we experienced as we wove our safe digital places. The second narrates how the safe place became part of a collaborative and political writing process. The third describes what we felt had changed for us through the process and the fourth is a reflection on our intergenerational conversations across time and place as we wrote this chapter. 


\section{One: Writing from Confinement}

WoN (Wendy): In 1997 I had just come back to Rome from a trip to Uganda, tired and on a run of meetings I was organizing, with just two weeks before a trip to Berkeley where I would be meeting other members of the WoN project in a long planned public encounter with Donna Haraway. That trip I never took in person, as I found myself bleeding and in danger of an early miscarriage. I was instead confined to bed-rest, accompanied by my three-year-old, and all the notes for the meeting, which I followed via email. In those days you had to use the modem attached to the telephone line. E-mailing cost, the same as a local phone call, which was timed. I would get out of bed late morning and head to the desk-top computer (there were no laptops then) and put in the modem to download the email message sent from the night before. I would then write back comments, offline, before plugging the modem and sending messages off, and then back to bed until the next day. It was a very strong cyborg moment for me. I felt, for the first time, through this technology connected to a meeting that was very important to me, happening on the other side of the world. There was such a strong sense of care being expressed by the group, who took turns to email me via the WoN listserv. As I was willing the baby to stay within me, I was also connecting digitally to people who cared enough to inform me about the meeting, knowing how much I had wanted to be there. Even as I lay prone on the bed, I was also able to create a place where I could connect and overcome the vulnerability of my body at that moment.

CC (Ximena): The project coincides with the uncertain times of Covid-19 during which the measures varied as much as the emotions they evoked in our bodies. The idea of replicating a safe place as a method of research emerged from the reflections of the solitude and distance I experienced while living in student housing. Due to the Covid-19 restrictions I had to engage in online lectures at ISS and avoid physical contact with the other students, who were my (only) home in the Netherlands. I remember being seated on my couch, located in one of the corners of my 20 square metre room, trying to come up with ideas of how to undertake research in such chaotic times, with all the existing restrictions and knowing that the intimacy and sensitivity of the topic required special care. Questions related to the relevance of doing a RP and engaging in academia flooded my mind, leading to a profound sense of demotivation. With the pandemic, all my previous 
priorities seemed to dissolve. I was far away from my family, friends and country, feeling worried, scared and lonely, but still having a master's degree to complete. At the same time, outstanding questions and inner conversations about my own sexuality became unavoidable, probably also because the courses I was following-which were readjusted for the online mode-were related to the topic. Seated on the couch, I took the time to reflect about my own body, an unknown terrain I had not had the time and courage to explore. Many conscious and unconscious sensations/thoughts/emotions/memories intersected at that specific time and space: my questions about the relevance of a RP, the search for a topic and method, the process of self-exploration I had started, and the empathy that my cuir history has produced in me. This messy combination of sensing and feeling motivated me to create a safe place as a research method, which was met with a positive response by my supervisor. I had not known that something so personal and intimate could be part of academic knowledge! Now that I look back, my surprise indicated how internalized the sense of research needing to be "objective" and "neutral" was for me.

\section{Reflections (Wendy and Ximena)}

Our stories both share the aim to practice feminist research in embodied ways. We embrace and acknowledge how bodies, emotions and feelings shape our research process. Confinement and its resulting embodiments due to pregnancy, illness, mental instability or asceticism inform our experiences as it is informing our writing of this chapter.

Whether confined to bed-rest or to our houses (during Covid-19), and feeling restricted to express love and feel pleasure in certain ways has informed our need to create safe spaces/places. As feminists, confinement and restrictions have inspired our political action and our search to find possibilities in the unexpected and unconventional, yet very careful, forms of doing research. This speaks to the creativity that underlies feminist methodologies. Researching in a feminist way allows us to think creatively as we intentionally disrupt the normative.

What results from feminist research goes beyond the actual research process. Our experiences speak to relations of care and body politics that emerged in these places. Openly questioning why and for what we are researching is an integral part of the process. Care and love are expressions of how we embody feminism and how our lives as researchers are 
part of the web of relations we create with the human and the morethan-humans (animals, plants, sea, lakes, mountains and landscapes) in our surroundings. ${ }^{6}$

\section{Two: Care and Nurturing}

WoN (Wendy): Over the months of writing about digital technologies, the fears and hopes for new forms of communication, we began to share more personal stories. I found myself writing about my evolving pregnancy. After my weeks in bed, I returned to work and I then enjoyed a healthy pregnancy. I felt the care and concern about my life continued in WoN discussions. Others shared their own stories of motherhood. In fact, four children were born during the project. These stories of pregnancy and birth created a particular dynamic and we opened the discussion about what it meant to be, or not be, parents. While our sharing was about celebrating the nurturing of life, we also discussed choices around whether to have or not have children, and what was possible. One woman shared the deeply painful story of having 6 still born children before finally her 7th child survived. Another of being resigned to not being able to have children. Several wrote about choosing not to have them. Others shared stories of the difficult decisions around choosing to have abortions. These were conversations I could not have imagined having in person in the usual rushed meeting environment. The disembodiment and stretched sense of connection opened up the possibility to share vulnerability. In speaking about such intimate embodied ways of being, we were forming a safe place at least for that moment, crossing personal and political borders. It became a community where not only theoretical academic and political issues were being debated, but also profoundly personal issues could be shared.

CC (Ximena): The phone alarm went off. It was 2.30 a.m. in the Netherlands (7.30 p.m. in Ecuador). I needed to start preparing myself for our safe place session. As every Wednesday and Sunday, the days in

\footnotetext{
${ }^{6} \mathrm{We}$ are including relations of more-than-humans in recognition of how caring for others includes not only humans but the many beings we rely on to live and flourish. We are inspired here by Val Plumwood's notion of Earthothers (1993) and Maria Puig de la Bella Casa's (2017) writing on care and more-than-human worlds. The chapter by Karijn and Leila (Chapter 2) in this book explores this more deeply.
} 
which we met, that night I could not sleep well. I was nervous of not waking up on time. I jumped out of bed to avoid falling asleep again. While I was getting dressed, I reflected on the topic of that session "stories of oppression and discrimination related with the 'unnatural' discourse". One of the Copensantes volunteered to prepare the session with me and proposed the use of poetry as our medium of discussion. She suggested that everyone could come with a poem evoking the feelings and emotions that being called "unnatural" generated in us, that way no one would feel pressured to narrate (painful) stories, if they did not feel comfortable. The Copensantes took turns to lead the sessions and propose artistic expressions to explore together. With this dynamic, my role as the "researcher" started to be less loud. Their ideas and creativity took over. This made it less of a space for constructing an RP and more a place to be together, share and care about each other. When this last thought was crossing my mind, I finished my tea in the silence of 2.50 a.m. and started to turn on the computer, not realizing how much that session would change us. After checking on each other, we shared our poems and stories. We spoke about what had been silenced for a long time, many of the stories were related to our coming-out processes with our families. Tears, smiles, and support travelled over the Internet waves. Once the session was over, I went back to bed around 5.30 a.m., finally finding the beginnings of the answers to my inquiries about the relevance of my RP and my engagement in academia.

\section{Reflections (Wendy and Ximena)}

Despite 20 years of difference, our experiences both demonstrate that feeling safe is essential for radical acts and expressions to happen. Stories and feelings that were silenced elsewhere could be expressed in these digital places by creating trust, care and respect. These values did not emerge right after agreeing on the creation of these projects, they were rather collectively created, and their co-creation was a fluid and uncertain process that took time, intention and negotiation. In fact, a safe place "needs to be understood as a verb, not a noun" (Argüello, 2020).

During these processes of co-construction, safeness did not imply the absence of uncomfortable feelings. Having a safe place allows for vulnerability to exist, together with all the difficulties that we experience when expressing our uncertainties. By creating safe places, we created places of fluidity where nothing needs to conform to norms. This was how we cuired/queered feminist methodologies. Only malleable and changing 
places of experiment would have allowed radical acts of border crossing. Not only the idea of neutrality and objectivity was challenged, but also the ideas of what kind of feelings should we allow to exist. This gave room to the emergence of knowledge from collective processes of (sometimes uncomfortable) questioning, problematizing and deconstruction.

Our stories both speak about safety and trust, although their actual practices differ in each story. Since feminist methodologies pay attention to particularities and aims to produce situated knowledge, safeness is necessarily contextual. It results from the negotiation among particular subjectivities in a particular time and a particular (digital) space, corresponding to a new culture of safeness that pertains to a particular (digital) place.

Coming from our histories as feminists and cuir/queer, coinciding in the construction of our safe spaces/places and demonstrating its relevance across time, the need to care guided our digital exchanges. The emergence of empathy and respect were a consequence of caring about each other's stories, lives and emotions. Care motivated the conversations to keep existing despite distance and time. Due to the physical limitations of the digital landscape, care motivated us to think creatively and find ways to express gestures of support. On pixelated and flat screens, limited by text, or allowed by video, we experienced different ways to feel accompanied and heard, sometimes through words and other times through art.

\section{Three: Transitions}

WoN (Wendy): As we ended the project, the connections we had made in WoN morphed into another project called women and the politics of place (Harcourt \& Escobar, 2005). The WoN conversations had allowed for the possibilities of even deeper conversations. In the project on women and the politics of place, we built on the WoN experience to theorize how digital connectivity was one of the places (cultures) women could create, the body being the first. What had emerged from WoN is how the internet was not confined to specific expert knowledge which required technological knowhow but was something feminists could engage with and shape. I recall when I was writing up my chapter "cyborg melodies" (Harcourt, 1999), I reflected on how connections about our personal and embodied lives were interwoven with stories of how we were using 
the technologies materially. One woman described how she was literally putting up the physical infrastructure needed to connect islands in the Pacific. Others shared their advocacy strategies for equity in the ICT policy board rooms. Our deeply felt personal stories were also marked by the darker side of the internet. We discussed how capitalist corporate and military interests were determining the internet. The fears of what sort of world had produced the internet can be seen reflected in the popular (now cult) film "The Matrix" (1999). The film was released with immediate popularity in the same period we were writing. The Wachowskis sisters' (who are transwomen) sci-fi horror film was released in 1999. In the film technology takes over humanity. Humans are plugged into the Matrix (a computer simulated programme) as a source of electrical and heat energy by the Artificial Intelligence that rules the world. Humans sleep throughout their entire lives in a simulated dream created by the Matrix.

Our WoN project helped us confront these fears, and think through the possibilities of the internet. We found ways to communicate in a place of safety, despite the newness. The moments of email connectivity were used to share intimate and important moments in our lives. At the same time, we were aware that this technology was not innocent, even if not necessarily the Wachowskis' monstrous vision. We discussed how governments, corporations, technicians and military research set the rules that could constrain our access and use. However, in that moment, and in that community, we felt ICTs had opened up a world where we could be freed from material constraints and let our imagination for a positive feminist world emerge and flourish.

CC (Ximena): Several times we discussed the potential of the safe place to generate empathy among us and from that empathy understand our histories in different ways; to be receptive and respectful. Learning from each other became almost our mantra. All this was happening online, a site that I did not trust at the beginning of this research journey. My scepticism towards the online environment was slowly being replaced by my curiosity of all the possibilities it could bring for creating safe places, and for us, as cuirs, to exist, interact and speak up. At the same time, in cyberspace everything was different. Feeling, sensing and interacting did not mean the same. It is impossible to allocate this difference to dualisms such as: personal/impersonal or better/worse. The differences were far more complicated than that. Lockdown due to Covid-19 was not only a period to re-learn in-person interactions: distances, lack of contact, when 
and how to touch our faces, when and how to cough... It was also a time to re-learn how to interact online. Although the internet existed already before the global outbreak, online interactions changed when they became the norm to replace in-person interactions. In our sessions, when hugging or holding our hands was not possible, tears and pain had to be addressed through other forms, such as singing for each other, dedicating songs, reading poems or simply contemplating the screens, motionless and in silence but with evident facial gestures that emanated love.

\section{Reflections (Ximena and Wendy)}

Through these safe spaces/places we used technology to create places of hope and change. This feels particularly brave knowing the dangers of technologies that are driven by the worst of capitalist consumerism, invade peoples' privacy and are used for hate and political campaigns, death and destruction (Sassen, 2007; Wyatt, 2008; Youngs, 2006). We know it is almost impossible to avoid those powerful structures that have constructed the social media that are so crucial to our being able to communicate and create safe and trusting places. But power is not all vertical and all invasive, there are small projects that exist and flourish within and despite the evasive patriarchal capitalist system (GibsonGraham, 2006). While we are part of a capitalist system, and need to be wary and vigilant, our cyborg existence in being openly feminist creates possibilities that empower and create change.

We argue that feminist research is doing politics by adopting a method that pushes against the normative positivist way of understanding knowledge. Our shared fascination for bodies as a place for resistance drove us to find ways to do research that are political. It may seem ironic to speak about body politics when the body seems absent in our digital engagements. But our stories run counter to the idea that we are disembodied in cyberspace. We show how the digital body not only exists but also resists. In our stories, the digital safe places became embodied and intimate (but public) sites to reclaim our material bodies.

As Haraway invited us twenty years ago, in the digital landscape embodiment needs to be rethought. Feeling, sensing and being close are experienced differently online. Digital bodies acquire the size and shape that technologies allow them to take. One becomes text, image or video in one-dimensional and flat screens. For this reason, feminist research has the possibility to shape and change social and cultural norms. In both WoN and CC, the participants learnt together how to reshape their 
embodied connections through active listening, building trust and confidentiality, care and love and to invent ways to participate and collaborate in the cyberspace.

\section{Four: Intergenerational Conversations Across Time and Place, a Dialogue}

Wendy: Our conversations have moved across time and place linking research experiences that are both about the present and the past stretching back 20 years. We began writing this chapter in my living room in The Hague. With its soft leather couches, old carpets, Japanese vases and carved Indo-Chinese furniture, this room is a place where feminists of different generations have met. Whether academics, students or visitors to ISS, we would meet over a glass of wine, in order to converse, read and write together. When writing this chapter, it was just Ximena and I who could meet, carefully social distancing. First, we talked over cups of tea about Ximena's MA research. We then moved beyond the formalities of supervision, to elaborate what we could write about together. We were excited about exploring the connections between Ximena's research on creating digital places and my writings - two decades ago-on creating culture in cyberspace. Over the months as we have continued to write, our room to meet has shifted from the living room in The Hague to a digital place, as Ximena returned to Ecuador and I to Rome.

Ximena: During times of restrictions and uncertainties, the cyberspace became an opportunity for rebellious bodies and provocative methods of research to exist. Our conversations about these exciting possibilities were the point of departure for Wendy and I to connect on different levels. Despite (and probably because) our feminisms are informed by different histories and struggles, we found ways in which they meet not only to work together but to find courage in each other. Our connection crossed the professional and very fast became a relation of sharing ethical concerns, feminist hopes and love for small presents of nature like flowers and sunsets. That connection brings us together in this chapter and motivates our desire to put our experiences in conversation. We reflect on how our feminist lenses allowed us to find possibilities in unexpected and (sometimes) criticized mediums, such as cyberspace and art. Emerging from our common hope in the ability of these spaces/places to contribute to everyday politics, this chapter narrates our exploration of 
different technologies and unconventional approaches to them, as means for our research and activism. First, connecting in-person in Wendy's living room and planning together how to later write this chapter through our machine selves. Six hours of difference and thousands of kilometres separate us. Yet, we have found-in a pixelated and flat screen-a way to recall our feminist experiences together.

Wendy: As I write this in lockdown in Rome, Italy, I look forward to speaking to Ximena this evening, late here, afternoon there. It feels like we just continue conversations but in a different space. What is odd is how normal that is, during Covid-19 lockdown, I connect and feel sane pushing down the sense of panic about the rising figures, the difficulties to move from home.

I recall how in the late 1990s "Information and Communication Technologies" also created a sense of global panic. The internet was viewed with fear and concern-would computers take over the world? The uncertainties we are facing with the Covid-19 pandemic are different, as we are now so used to communication technologies and, the debates around data and privacy notwithstanding, the internet is solidly part of our everyday lives. Back then, it was a historical moment when the internet became accessible to ordinary people, and fast cheap ways of communicating, writing and doing research became possible for feminists. While we were using text rather than visual technologies, it appeared revolutionary that we could receive instant responses, share and have conversations that are intimate and where women's lives could be the subject and focus of technological discussions. In my conversations with Ximena, I became struck by the importance of cyberspace in my life as a feminist on both a political and personal level.

Ximena: Twenty years later, we continue to be surprised by technological advances and the fear towards them still remains. Just as Wendy recalled the Matrix film in her third story "Transitions" to reflect on how internet was experienced twenty years ago, I write this as my mother watches the documentary "The Social Dilemma" in the living room. This 90-minute film shows the fears and scepticism that we experience nowadays, particularly towards social media and the scary power they have to manipulate behaviour and social interactions. In fact, surveillance, manipulation of private data and human psychology are some of the more common fears that are ascribed to technology nowadays. Microphones and cameras of our devices appear to be spies in our pockets that accompany us 24/7. During Covid-19 when digital interaction has become the 
norm, there is still a general scepticism towards digital communications. It is not only seen as dangerous but also as something that distances, disembodies, and even dehumanizes us.

In this context and without denying these dangers, we come together to queer these perceptions and use this so feared "threat" to find hope for feminist and queer/cuir political action and research. A desire that is informed by our curious, audacious and queer/cuir feminisms.

\section{Conclusion: The Transformative Potential of Feminist Methodologies}

Our chapter has shown the disruptive possibilities of doing feminist research that challenge the norms of social science research techniques that aim to "objectively" collect qualitative or quantitative data via surveys, questionnaires, interviews and case studies. Our evidence is our feelings, experiences and emotions. We think about our feminist actions not as subjects of research but as reflections on our actions in using the internet to create feminist and queer safe places. Aware of our privileged positionings, we have used our form of writing as a vehicle of research in order to allow us to discuss our changing relationship with technology from a personal as well as political perspective.

Our main methods are self-reflection and storytelling. We analyse rather than categorize the email messages, the videos and digital photos along with our own memories and conversations as authors who produced the digital places with others. By using dialogue and storytelling, we have not tried to produce case studies that are fixed products of our research. Rather, in a fluid and open way, we have meshed conversations about different moments across time and space. The writing has been part of the doing, part of our own sensing feeling about the need for feminist safe places. We have paid attention to our and others' emotions, as part of our feminist ethics. We have recognized the importance of acknowledging and embracing emotions as part of the research process. We see such recognition and openness to emotions as particularly important in these troubling Covid-19 times. In this sense we have embraced feminist methodology as having a transformative potential for our sense of well-being and hope.

While exploring the possibilities of digital communication we also had to pay attention to the restrictions of online communication. There is a 
sense of loss in communications when you cannot touch, hug, feel the body language when in person. Ironically, the digital places allowed us to speak about embodied realities and tensions which in person we may not have found easy or possible. To return to Haraway's (1991) image of the cyborg, we created a digital embodied natureculture where the digital self could shape the material self. So, while these places were not where people physically met, they were real in feeling and sensing and in memory. The places held care and love and provided support personally and politically as fears and hopes around pregnancy or gender/sexual expression were shared and felt.

In this way, the places we created contributed to a digital exploration of body politics. In the case of WoN these contributions were fourfold. First, it was a space for participants to voice their embodied experience of pregnancy, miscarriage and abortion. To speak about abortion, miscarriage and doubts around pregnancy which were in many places taboo in public was a radical act. Second, WoN contributed to the shift in body politics in development discourse by writing about these concerns in an international project funded and endorsed by a UN body. Third, WoN in discussing technology and body politics from the perspective of different cultures was also challenging western ways of seeing, further politicizing embodied digital interactions. Fourth, WoN conversations raised twenty years before "me too" the spectre of online sexual harassment and the need to prevent online stalking. We were looking at how ICTs connect the private to the public, the local to the would-be global, intimate, face-to-face communications with distant, non-proximate intimacies. They reconfigure our sense of embodiment and understanding of mind-body relationship, and social-ness and our entanglement with the environment (Franklin, 2010: 367) (see Fig. 5.4).

In the case of $\mathrm{CC}$, the way body politics was experienced reflected the borders crossing/disruption intention through which the project was created. First, this place allowed rebellious bodies to speak up and exist, something that was sometimes not even possible in the material places from where they were connected (home). Second, CC was a place for singular voices to meet the collective and become louder. Finding the "we" voice within diversity was not easy, especially when the aim was to also highlight the particular, but it was necessary for collective politics to happen. Third, CC showed the political character that digital art holds, especially related to the body. It allows the unspeakable to be said and travel across time and space navigating internet waves and inspiring 


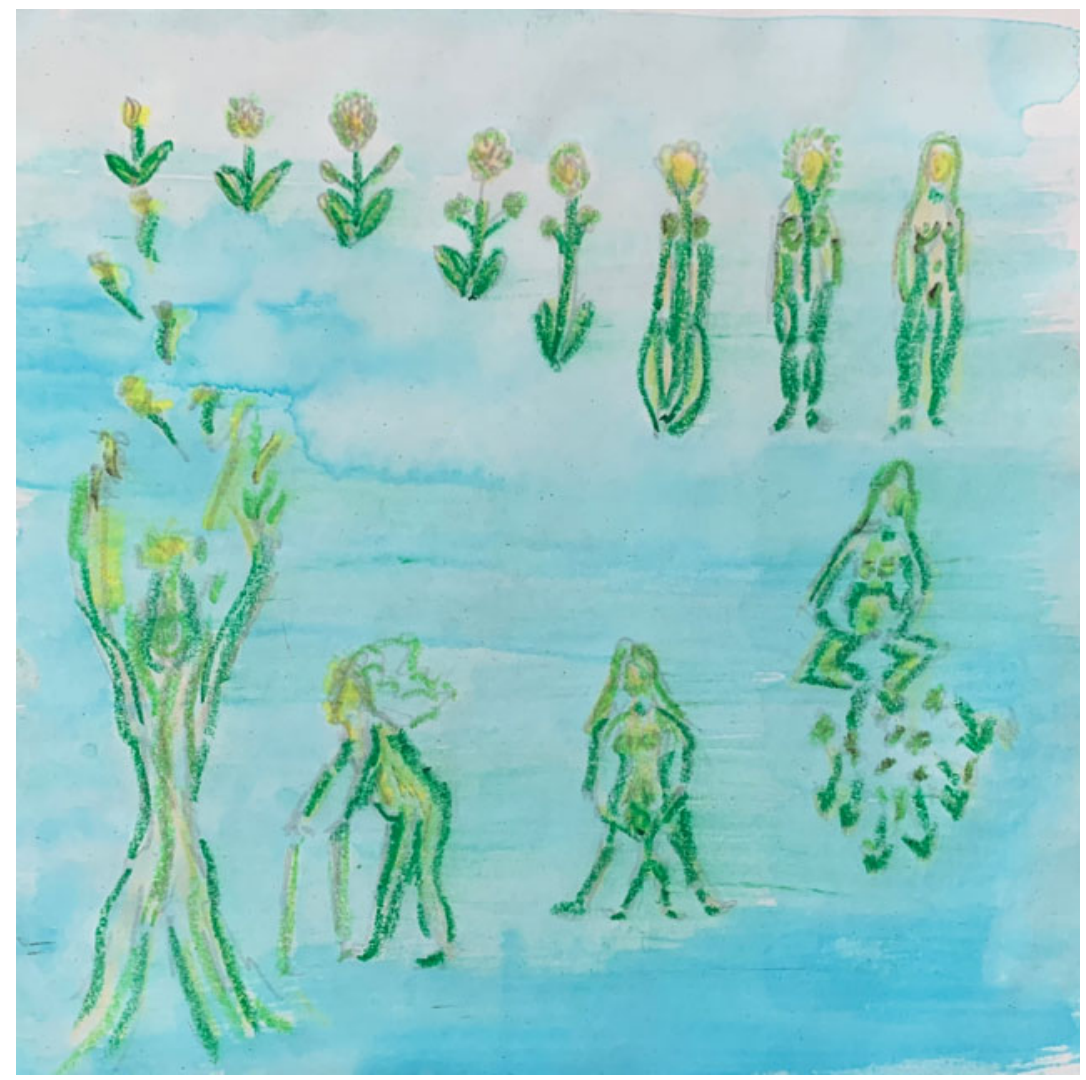

Fig. 5.4 Feminist socionature entanglements by Wendy

This drawing captures my sense of body is connected to the Earth, in a cycle of ageing, over time, growing, giving, changing, returning. The blues and greens are about the blending of water and growing plants, like the woman's life you see depicted moving as in human form from seed to tree to the soil

other transgressing bodies to resist. And fourth, CC opened conversations about gender, sexuality and pleasure beyond anthropocentric understandings that ascribe sexuality to uniquely the cultural domain. This showed the potential of body politics to be explored beyond the human, to be 


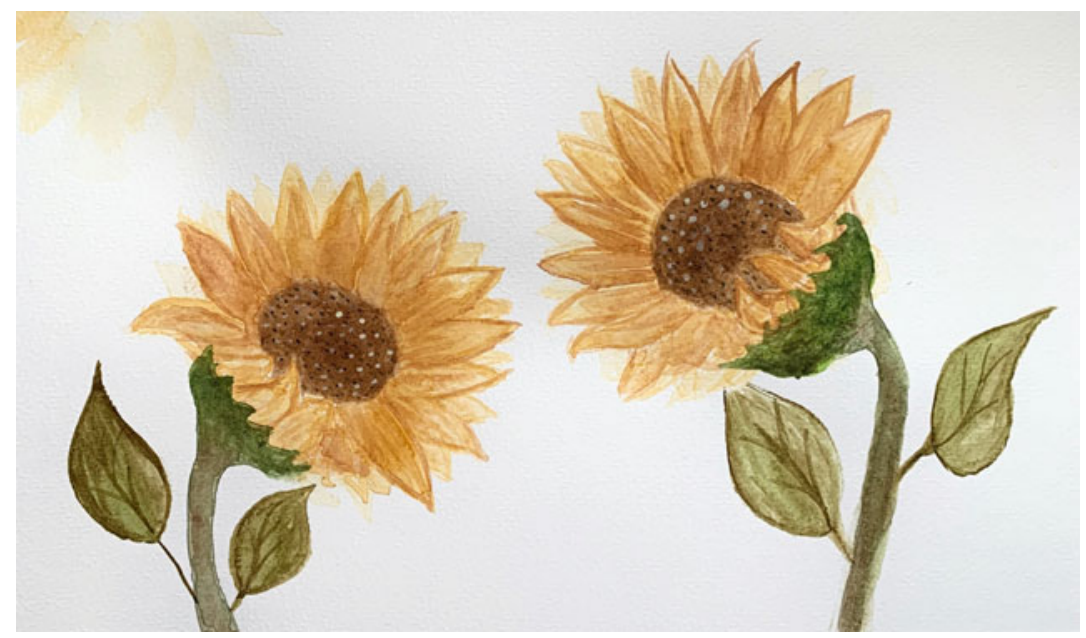

Fig. 5.5 Girasoles: Conexión y Fortaleza Sunflowers: Connection and strength by Ximena

One of the Copensantes shared in CC: "When the sun is not there, sunflowers gather energy from each other... they become the sun for the others. Just as we do in CC!" This drawing represents the strength and connection that travelled online opening possibilities of resistance and transformation

questioned through audacious cuirnaturecultures and become an important political tool for justice for human and more-than-human others (Fig. 5.5).

\section{EPILOGUe}

Writing this chapter was fun. We had planned to complete it in our digital living room while watching Grace and Frankie Season 7 (which was sadly postponed due to Covid-19). We discovered early on our love of that Netflix sitcom-and how feminist methodology goes way beyond academe. We see the potential of many different feminist digital places that travel across time and space and are unashamedly part of our everyday lives to express, connect and build loving and caring relations. We know things will change, and we are part of the change, the machine in us will overcome the monsters. We trust our cuir/queer and feminist selves to 


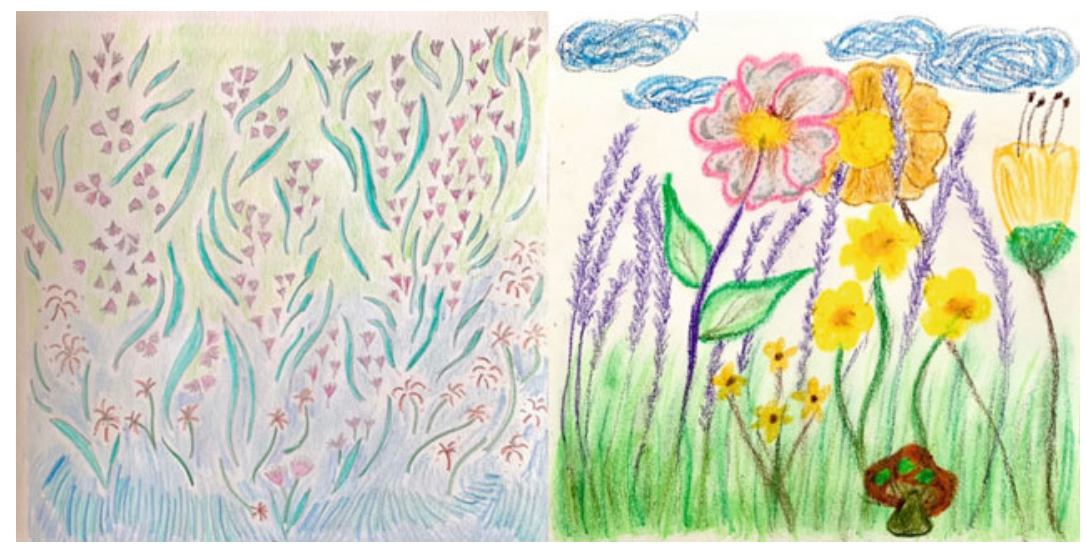

Fig. 5.6 Finding Spring Together by Wendy and Ximena

These two last drawings we did together watching re-runs of Grace and Frankie, laughing aloud, reunited in Wendy's living room in The Hague. Unexpectedly we could come back together to finish the chapter in March 2021. Our drawings celebrate spring and how we rediscovered the same care and connection we had also been constructing in the digital space

continue to connect, find safety and flourish in and out of digital spaces (Fig. 5.6).

Acknowledgements Thank you to the editors of this volume for their comments and encouragement and to our friends past, present and future, too many to name. Wendy's work has received funding from the European Union's Horizon 2020 research and innovation programme under the Marie Skłodowska-Curie grant agreement No. 764908 WEGO-ITN "Well-being, Ecology, Gender and Community"-Innovation Training Network.

\section{REFERENCES}

Argüello, X. (2020). Becoming a free dandelion: Exploring rebellious cuirnaturecultures through the creation of an online safe place with cuirs in the Andean Ecuador during Covid-19 times (ISS Working Paper No. 679). ISS. Bell, D. (2010). Queernaturecultures. In C. Mortimer-Sandilands \& B. Erickson (Eds.), Queer ecologies sex, nature, politics, desire (pp. 134-145). Indiana University Press. 
Eisner, E. (2008). Art and knowledge. In G. Knowles \& A. Cole (Eds.), Handbook of the arts in qualitative research (pp. 3-12). Sage Publications.

Escobar, A. (2007). Worlds and knowledges otherwise. Cultural Studies, 21(23), 179-210. https://doi.org/10.1080/09502380601162506

Franklin, M. I. (2010). Sex, gender and cyberspace. In L. Shepherd (Ed.), Gender matters in global politics (pp. 327-346). Routledge.

Gibson-Graham, J. K. (2006). Post Capitalist Politics. Minnesota University Press.

Haraway, D. (1991). A cyborg manifesto: Science, technology, and socialist feminism in the late twentieth century. In Simians, cyborgs and women: The reinvention of nature (pp. 149-181). Routledge.

Haraway, D. (2003). The companion species manifesto: Dogs, people, and significant otherness (Vol. 1). Prickly Paradigm Press.

Harcourt, W. (Ed.). (1999). Women@Internet: Creating cultures in cyberspace. Zed Books.

Harcourt, W., \& A. Escobar. (Eds.) (2005). Women and the Politics of Place. Kumarian Press.

Harcourt, W., \& Bauhardt, C. (Eds.). (2019). Conversations on care in feminist political economy and ecology. In C. Bauhardt \& W. Harcourt (Eds.), Political ecology and the economics of care: In search of economic alternatives (pp. 1-15). Routledge.

Harding, S. (1992). Rethinking standpoint epistemology: What is "strong objectivity"? The Centennial Review, 36(3), 437-447.

Lorenz, R. (2012). An Introduction. In R. Lorenz (Ed.), Queer art: A freak theory (pp. 15-30). Transactions Publisher.

Massey, D. (1994). A place called home? In D. Massey (Ed.), Space, place, and gender (pp. 157-173). University of Minnesota Press.

Plumwood, V. (1993). Feminism and the mastery of nature. Routledge.

Puig de la Bella Casa, M. (2017). Matters of care: Speculative ethics in more than human worlds. University of Minnesota.

Rose, G. (1997). Situating knowledges: Positionality, reflexivities and other tactics. Progress in Human Geography, 21(3), 305-320. https://doi.org/10. $1191 / 030913297673302122$

Sandilands, C. (2005). Unnatural passions? Notes toward a queer ecology. Invisible Culture an Electronic: Journal for Visual Culture, 1(9), 1-31.

Sassen, S. (2007). A sociology of globalization. W. W. Norton.

Sörensson, E., \& Kalman, H. (2018). Care and concern in the research process: Meeting ethical and epistemological challenges through multiple engagements and dialogue with research subjects. Qualitative Research, 18(6), 706-721. https://doi.org/10.1177/1468794117743466

Stein, R. (2010). The place, promised, that has not yet been: The nature of dislocation and desire in Adrienne Rich's Your Native Land/Your Life and 
Minnie Bruce Pratt's crime against nature. In C. Mortimer-Sandilands \& B. Erickson (Eds.), Queer ecologies sex, nature, politics, desire (pp. 285-308). Indiana University Press.

Trujillo, G. (2016). La protesta dentro de la protesta. Activismos queer/cuir y feministas en el $15 \mathrm{M}$ [The protest within a protest. Queer/cuir activism and feminists during 15M]. Encrucijadas, 12, 1-18. Retrieved September 23, 2020, from https://recyt.fecyt.es/index.php/encrucijadas/article/view/ 79088

Walsh, C. (2016). On gender and its “otherwise." In W. Harcourt (Ed.), The Palgrave handbook of gender and development (pp. 34-47). Palgrave Macmillan.

Wyatt, S. (2008). Feminism, technology and the information society: Learning from the past, imagining the future. Information, Communication and Society, 11(1), 111-130. https://doi.org/10.1080/13691180701859065

Youngs, G. (2006). Global political economy in the information age: Power and inequality. Routledge.

Open Access This chapter is distributed under the terms of the Creative Commons Attribution 4.0 International License (http://creativecommons.org/ licenses/by/4.0/), which permits use, duplication, adaptation, distribution and reproduction in any medium or format, as long as you give appropriate credit to the original author(s) and the source, a link is provided to the Creative Commons license and any changes made are indicated.

The images or other third party material in this chapter are included in the work's Creative Commons license, unless indicated otherwise in the credit line; if such material is not included in the work's Creative Commons license and the respective action is not permitted by statutory regulation, users will need to obtain permission from the license holder to duplicate, adapt or reproduce the material.

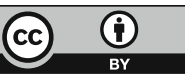

